\title{
Commercial Correspondence: Pragmatics, Semantics, Syntax
}

\author{
Guryeva Natalia Yurevna ${ }^{1}$ \\ Associate professor, Russian State University for the Humanities, \\ Moscow, Russia.
}

(date of receiving: January, 2018; date of acceptance: June, 2018)

\begin{abstract}
This article is devoted to analysis of specific features of contemporary Russian business correspondence. The functioning of commercial letter texts used in practice of verbal communication between business partners and verbal situation of organization of business correspondence examines in present text as a process formed in occasion with existed tradition of contacts in commercial sphere and in the same time in context of contemporary tendencies of liberal and democratic discourse of social communication. Practice of interpretation the text of business letter, different semantic aspects of this text, under-textual content of information transcended in written form is studying in concrete context of verbal communication. Positioning of participants of communication, constructed between them communicative distance and used by them verbal tactics connected with business ethic are examining in paper in quality of forms of verbal activity. Using in paper method of conceptual analysis of semantic features of business letters gives possibility not only to understand content and to make evaluation of text but also to determine mostly successful strategy of verbal contact (framing) with objective of achievement practically important and scientifically based results. Business correspondence is studied in paper as a conceptual product with all framing features and particularly by determined pragmatic scenario.
\end{abstract}

Keywords: Commercial Correspondence, Business Letter, Verbal Communication, Language Semantics, Text Style, Verbal Distance.

1. Email: gri_lanskoi@list.ru 


\title{
Коммерческая корреспонденция: прагматика, семантика, синтаксис
}

\section{Гурьева Наталья Юрьевна ${ }^{1}$}

Доцент, Российский государственный гуманитарный университет, Москва, Россия.

(дата получения: январь 2018 г.; дата принятия: июнь 2018 г.)

\begin{abstract}
Аннотация
Статья посвящена анализу особенностей современной российской деловой переписки. Функционирование текстов писем коммерческой направленности, используемое в практике речевого взаимодействия деловых партнеров, и речевая ситуация ведения деловой переписки рассматривается в представляемом тексте в качестве процесса, обуеловленного сложившейся традицией контактов в коммерческой среде и в то же время современными тенденциями формирования либерального и демократического диекурса социальной коммуникации. Практика интерпретации текста делового письма, различные семантические аспекты этого текста, подтекстное содержание передаваемой в письменной форме информацин изучается в рамках статьи в конкретном контексте речевого взаимодействия. Позиционирование участников коммуникации, выстраиваемая между ними речевая дистанция и применяемые речевые тактики делового этикета рассматриваются в статье в качестве форм речевого действия. Применяемый в статье метод конщептуального анализа семантических свойств деловых писем дает возможность не только понять содержание и осуществить оценку текста, но и определить наиболее успешную стратегию речевого взаимодействия (фреймирования) в целях достижения практически значимых и научно обоснованньх результатов. Деловая переписка рассматривается в статье как концептуальный продукт, обладающий всеми признаками фрейма и, в частности, заранее определенньм сценарием.
\end{abstract}

Ключевые слова: коммерческая переписка, деловое письмо, речевая коммуникация, языковая семантика, стиль текста, речевая дистанция.

1. Email: gri_lanskoi@list.ru 


\section{Введение}

Функционирование текстов коммерческих писем в речевом взаимодействии деловых партнеров (адресанта и адресата) и речевая ситуация деловой переписки, т.е. прагматика текста, обусловлены как исторически сложившейся традицией, так и современными тенденциями выстраивания либерально-демократического дискурса коммуникации. В условиях современного общества прослеживаются новые тенденции, обусловленные в среде коммерческой деятельности распространением как минимум на формальном уровне рыночных равноправных отношений не только между взаимодействующими, но и между конкурирующими субъектами. Поскольку с точки зрения языкознания данные тенденции находят отражение, главным образом, в осуществляемой деловой переписке, ее комплексный анализ может представлять не только собственно филологический интерес, но и ценность с точки зрения воспитания необходимых навыков речевого этикета у занимающихся предпринимательством граждан различных стран. В практической сфере исследовательская работа в данной сфере может послужить основанием для создания методических рекомендаций по ведению деловой коммерческой переписке, которые могут быть существенны в том числе для актуального в настоящее время во многих странах мира научного направления когнитивной лингвистики.

Исследование особенностей коммерческой корреспонденции осуществлялось к настоящему времени параллельно в трех направлениях теории литературного языка, методики и практики делового этикета и теории документоведения. В области теории литературного языка наиболее значимыми с точки зрения разработки темы статьи стала монография В.П. Григорьева, посвященная особенностям семантики современного литературного языка (Григорьев В.П., 1993), и статья В.И. Заботкиной, в которой вопросы языковой семантики и стилистики речевой коммуникации 
нашли совмещение с современными представлениями о когнитивной лингвистике (Заботкина В.И., 2015). В сфере изучения методики и практики делового этикета вопросы речевой коммуникации применительно к ведению деловой корреспонденции в целом были наиболее полно изучены В.И. Венедиктовой ( Венедиктова В.И., 1994) и Р. Теппером (Теппер Р., 1997), которые исследовали разнообразные проявления норм и отклонений от нормативных требований делового этикета на примерах российской и зарубежной деловой переписки. В области теории документоведения наибольшую значимость для проблематики статьи имеют исследования, подчеркивающие коммуникативную ценность документа и его определяющую роль в регулировании социальных отношений именно с точки зрения языкового и в существенной мере производного от него функционального содержания. Наиболее актуальные и современные наблюдения и выводы в данной области сделаны в статьях А.В. Соколова (Соколов А.В., 2009) и Г.Н. Ланского (Ланской Г.Н., 2017).

Несмотря на сформированность в указанных, а также в некоторых других исследованиях по обозначенной проблематике ряда значимых методологических, теоретических и методических наблюдений и выводов, следует подчеркнуть, что специальных исследований, посвященных конкретным языковым особенностям коммерческой переписке, в настоящее время практически не существует. В представляемой статье тексты коммерческой корреспонденции впервые анализируются как объект и как средство фреймовой коммуникации. Также в системном ключе на основе совмещения лингвистических и документоведческих представлений, а также ряда положений теории управления продемонстрирована прямая прагматическая связь между применяемыми в текстах делового письма языковыми средствами и функционально-целевой значимостью данных текстов. Кроме этого, в значительной мере впервые в рамках проведенного 
исследования продемонстрированы примеры грамматических синтаксических конструкций, используемых в различных по жанровой и видовой принадлежности русскоязычных текстах коммерческого содержания и назначения

\section{Основная часть.}

В связи с ситуацией коммерческой переписки особого внимания заслуживает социально-этикетная сторона речи. В частности, то, что традиционно русская деловая корреспонденция не предполагает сокращения речевой дистанции между коммуникантами: информативный диалог не должен становиться навязчивым, активно вторгаться в личное пространство адресата. Подобная стратегия, характерная для западной, прежде всего американской (Р. Теппер, 1995), традиции составления текстов коммерческой корреспонденции, может спровоцировать коммуникативный конфликт: моделируется эмоциональная рефлексия отчуждения, недоверие в отношении адресанта, провокативности его позиции.

В результате игнорирования несоответствия национальных представлений о социально-этикетной стороне речи, о соотношении между участниками коммуникации в речевых актах и, как следствие выбора сценария текста коммерческого письма по западному образцу возможен также комический эффект при восприятии сообщаемой информации. Прежде всего это относится к оформлению этикетной рамки делового письма и содержания текста постскриптума. В соответствии со сложившейся традицией для русской деловой переписки характерно подчеркнутое речевое неравноправие позиций участников коммуникации. В частности, проявляется сознательно акцентируемое в соответствующих этикетных формулах (фразеосхемах) уважение к адресату, демонстрирующее его особую статусную роль в моделируемой речевой ситуации. 
Эту функцию выполняет, к примеру, употребление так называемого этикетного «Вы» при обращении к деловому партнеру, в результате чего элементарный грамматический концепт личного местоимения, имеющий формально-грамматический контекст, приобретает особую семантическую функцию, трансформируясь в связи с этим в концепт-фрейм. Использование этикетного «Вы» в современном русском языке возможно только в деловой переписке и поэтому ассоциативно связано с другими лексикосемантическими языковыми средствами при передаче информации, т.е. предполагает стилистическую маркированность текста в целом. К тому же этикетное «Вы» как концепт-фрейм вызывает в сознании адресата непосредственную ассоциацию с конкретной деловой ситуацией речевого взаимодействия (Баранов А.Н., Добровольский Д.О., 1997).

В качестве примера рассмотренной речевой ситуации при составлении делового письма можно привести следующий пример коммерческого делового предложения:

«От имени Банка Русский Стандарт я рад приветствовать Вас!

Являясь нашим клиентом, Вы зарекомендовали себя с самой лучшей стороны, и я с удовольствием хотел бы поблагодарить Вас за плодотворное сотрудничество. Именно таким клиентам мы стараемся в первую очередь предлагать наши самые новые продукты, все самое современное и интересное.

Со дня основания Банка Русский Стандарт приоритетным направлением для нас являлось создание и предложением клиентам уникальных программ, услуг и продуктов. Отличительной особенностью наших предложений является то, что все они призваны помочь людям решать наиболее важные и жизненные задачи. Самым известным проектом нашего Банка является организация программы потребительского кредитования населения.

Сегодня мы предлагаем лучшим клиентам, в первую очередь Вам, нашу самую новую разработку - депозитную программу «Русский Стандарт». 
Создавая этот продукт, мы старались сделать его не только интересным и отвечающим самым взыскательным требованиям наших клиентов, но и высокотехнологичным, удобным и, не в последнюю очередь, красивым. Являясь лидером на рынке потребительского кредитования, мы не могли себе позволить создание депозитного продукта, не отвечающего самым взыскательным требованиям».

Нарушение традиционно сложившегося представления о соотношении между участниками коммуникации, нарушение принципа релевантности, семантическое несоответствие коммуникативной тактики адресанта коммуникативному запросу адресата безусловно влияет на степень практической применимости результата речевого взаимодействия и его социальной значимости. Так, обращение в рамках этикетной формулы приветствия по имени «дорогой» (в русской традиции характерно только для личной переписки с предельно сокращенной речевой дистанцией) в коммерческой корреспонденции может быть воспринято либо иронически в отношении адресанта, что при отсутствии близких, дружеских отношений не соответствует национальному сценарию серьезного информационного диалога, либо способно спровоцировать коммуникативный конфликт. Интерпретация текста, его подтекстного содержания, косвенных и скрытых смыслов, т.е. прагматических пресуппозиций, в перлокутивном аспекте речевого взаимодействия при несоблюдении этикетных норм не способствует оптимизации конструктивного диалога, т.к. демонстрируется не только невнимание к сложившимся национальным традициям и даже пренебрежение ими, но и навязывание чужих стереотипов речевого поведения.

Подобные тенденции позиционирования коммуникантов, выстраивания речевой дистанции и речевых тактик, характерные для современного либерально-демократического дискурса, основаны на сознательном отказе от условностей и стереотипов делового этикета, наиболее ярко и очевидно 
проявляясь в реквизите делового письма «постскриптуме». Значение постскриптума, особо подчеркиваемое Р. Теппером (Р. Теппер, 1995) как способа воздействия на адресата в перлокутивном аспекте с целью моделирования определенных эмпатий; эмоциональное отношение к передаваемой информации для установления нормальных, доверительных отношений в практике российской коммерческой переписки также весьма неоднозначно. Сложившаяся в России практика регистрации и учета входящей и исходящей корреспонденции в современных государственных и негосударственных учреждениях предполагает ознакомление достаточно широкого круга сотрудников с содержанием писем. И рекомендации Р. Теппера по составлению текстов постскриптума, содержащего частную и даже в определенной степени конфиденциальную информацию (сведения о семейных отношениях - свадьбы, юбилеи, учеба детей; о неформальных встречах, прогулках, развлечениях) представляются не соответствующими нормам корпоративной этики.

Коммуникативная ситуация позволяет в рамках прагматики проанализировать и когнитивную семантику, и синтаксические особенности (коммуникативный синтаксис) коммерческой корреспонденции. В связи с тем, что процесс коммерческой переписки в рамках конкретной деловой ситуации представляет собой стандартно воспроизводимую систему обмена информацией, идентификацию событий с аналогичными, возникает возможность их категоризации. В соответствии с процессом категоризации деловое письмо может рассматриваться как многокомпонентный концепт, обладающий всеми признаками фрейма: наличием устойчивой структуры и смысловой рамки.

Жесткая и полужесткая композиционная схема составления текста делового письма, стереотипность языковых средств передачи информации обусловливает «метакоммуникативное определение ситуации, основанное на 
управляющих событиями принципах организации» (И. Гофман, 2003). В зависимости от предметного наполнения и, в частности, от темы и функции высказывания связный текст строится в соответствии с некоторыми структурными схемами, основанными на логической дифференциации. В соответствии с логическими особенностями выделяются следующие функционально-смысловые типы суждений в деловых письмах: определение, перечисление (описание или повествование), рассуждение, предписание.

Например, определение широко используется в типах текстов, раскрывающих содержание понятий и придающих смысл некоторым терминам. Оно применяется в текста делового письма в тех случаях, когда необходимо сообщить, какими отличительными признаками обладают те или иные предметы, или когда требуется разъяснить смысл какого-либо термина. Структура текста определения соответствует следующей формуле: Т1 $($ определяемое понятие $)=$ T2 (определяющая часть), что указывает на примеры явных определений, в которых определяемое понятие вынесено влево и не встречается в правой (определяющей) части. Так, в частности, статья 11 Устава г. Москвы «Основные понятия, используемые в Уставе» представляет собой так называемое номинальное определение, т.е. текст, разъясняющий словоупотребление: «городское сообщество - жители Москвы в своей совокупности»

В следующем примере приводится текет так называемого реального определения, в котором раскрываготя отличительные особенности класса предметов, о которых идет речь: «сберегательный сертификат - ценная бумага, удостоверяющая сумму вклада, внесенного в банк, и права вкладчика (держателя сертификата) на получение по истечении установленного срока суммы вклада и обусловленных в сертификате процентов».

Тексты - определения регулярно используются в нормативно-правовых документах (договорах, контрактах) для ограничения объема понятия и 
исключения возможности его двусмысленного толкования в процессе правоприменения.

Перечисление является типом текста, в основе которого лежит логическая функция конъюнкции. Данный тип текста представляет собой сложное суждение, части которого связаны сочинительной (соединительной или присоединительной) связью. Все части текста-перечисления могут рассматриваться в качестве конъюнкции входящих в него микротем - простых или сложных высказываний. Описание и повествование представляют собой подвиды перечисления как функционально-смыслового типа текста, отличающиеся соответственно статическим или динамическим принципом характеристики языковых явлений.

Признаками текста-описания являются закрытая структура, предполагающая максимальный трехкомпонентный объем описания; вневременность (статичность) суждений и грамматическая организация высказывания, при которой сказуемое-глагол представлено в форме настоящего времени, которое приобретает в свою очередь форму «расширенного настоящего), в которой все формы употребляемого глагола соотнесены с реальным моментом речевого высказывания. Формула текста описания может быть представлена в виде схемы $\mathrm{T}=\mathrm{T} 1+\mathrm{T} 2+\mathrm{T} 3$, в которой $\mathrm{T} 1$ обозначает признаки, свойства, отличительные особенности предмета речи; Т2 - признаки предметов, свойств, явлений, смежных с элементами группы Т1, Т3 - выявление или не выявление аналогий с предметами, сопоставимыми с общим планом приводимого описания. К числу текстов-описаний относятся, в частности, такие виды документов, как характеристика и рекомендательное письмо.

Текст повествовательного типа делового письма характеризуется открытой структурой; последовательностью перечисляемых в тексте действий (т.н. динамическим перечислением) и грамматической организацией высказывания, 
при которой связь между предложениями или частями предложений осуществляется с помощью предложных конструкций и деепричастных оборотов. Повествовательный тип изложений деловой коммерческой информации в нормативно-правовых актах используется только в структуре текста-предписания в случаях, когда предполагается изложение определенной последовательности предиисываемого действия. В такого рода текстах перечисляемые действия, как правило, обозначаются во вневременном качестве или в форме настоящего времени. К числу текстов-повествований относятся, например, такие виды документов, как автобиография, инструкция, правила использования чего-либо, порядок сборки чего-либо и т.п.

Рассуждение представляет собой тип текста, в основу которого положены логические отношения слов, характерные для выражения причинноследственной связи. Данный текст мало распространен в деловых текстах организационно-распорядительного характера вследствие их ярко выраженной регламентирующей направленности. Тексты-рассуждения используются при составлении писем-прошений - таких как жалобы, письма-претензии, исковые заявления, требующих аргументацию и доказательство приводимых сведений. Признаками текста-рассуждения являются закрытая структура с максимальным четырехкомпонентным объемом, предусматривающим в деловом коммерческом письме наличие косвенной аргументации; причинноследственная связь речевых компонентов и отсутствие формы повелительного наклонения при оформлении являющихся основанием рассуждения предложений. Формула текста-рассуждения определяется прямым или косвенным характером осуществляемого в деловой переписке аргументативного процесса. Непосредственное обращение аргументов и демонстрации (как основания суждения) к приводимому тезису является примером реализации прямого аргументативного процесса, в то время как при косвенном аргументативном процессе наряду с тезисом приводится одно или 
несколько суждений, противоречащих аргументируемому тезису. В частности, примером текста-рассуждения является текст претензии.

При построении текста-рассуждения требуется соблюдать следующие правила: тезис должен быть ясно сформулирован и не меняться в процессе доказательства; аргументы должны быть истинными, а их истинность должна быть обоснована независимо от содержания приводимого тезиса. Демонстрация аргумента при этом должна быть основана на причинноследственной логичности выдвигаемого тезиса, выдвигаемого из приводимых в коммерческой переписке аргументов.

Текст делового коммерческого письма, относящийся к типу предписания, создается и используется с целью побуждения к некоторым действиям путем выявления и одновременно смыслового ограничения их последовательности. Признаками данного типа текста делового письма являются открытая структура изложения; вневременной (статичный) характер суждений предписывающей (модальной) направленности и грамматическая организация высказывания, при которой все формы сказуемого-глагола соотнесены с реальным моментом речевого высказывания. В формуле текста-предписания $\mathrm{T}=\mathrm{T} 1+\mathrm{T} 2+\mathrm{T}_{п}$ элемент $\mathrm{T} 1$ обозначает наименование субъекта в соответствии с его функцией в деловой коммуникации, представляющей собой гипотезу высказывания, а элементы в сочетании Т2+Тп фиксируют последовательность или совокупность предписываемых действий, т.е. диспозицию высказывания.

Гипотеза и диспозиция представляют собой обязательные элементы текстапредписания. Последовательность их представления в тексте делового коммерческого письма отличается строго соблюдаемым расположением в виде прямого порядка слов, при котором гипотеза предшествует диспозиции. Диспозиция в рамках структуры коммерческой корреспонденции может быть выражена не только составом приводимого сказуемого простого предложения, но и несколькими предложениями, связанными отношением коньюнкции. 
Рассматриваемая логическая функция коньюнкции лежит в основе перечисления как формы построения текста, вследствие чего возникающая в предложении многочленная диспозиция представляет собой в результате описание или повествование с предписывающим модальным значением.

Конъюнктивные высказывания в рамках коммерческой деловой корреспонденции различаются в зависимости от структуры текстапредписания. Так, например, при тождестве агентного аргумента различаются предикаты высказывания: однородные сказуемые или сверхфразовое единство, соединительные синтаксические отношения (в частности, возможность замены бессоюзной связи союзом «и»). При совпадении агентного аргумента и предиката проводится разграничение аргументов с помощью предложений с однородными второстепенными членами или с однородными придаточными предложениями. При различении агентного аргумента и предиката с помощью детерминанта (предложения с детерминантом или с детерминирующим придаточным предложением) обеспечивается смысловое совпадение какоголибо иного аргумента деловых отношений.

Концептуализация (осмысление) передаваемой информации, т.е. концептуальный анализ семантики делового письма, предполагает не только понимание текста и умение его профессионально оценить, но и определить стратегию речевого взаимодействия (фреймирование) в целях достижения конкретных практических результатов. А категоризация деловых писем, семантика которых обусловлена конкретной речевой ситуацией, позволяет рассматривать коммерческую переписку как фреймовую сеть, построенную по определенному сценарию, который репрезентируется текстами различного функционального типа. Примером подобной фреймовой сети может служить:

1) информационное письмо (меморандум) с предложением сотрудничества; письмо-предложение сотрудничества; письмо-ответ на предложение сотрудничества; письмо-договор (контракт) о сотрудничестве; письмо- 
реприманд (претензия) о нарушении условий сотрудничества как один из возможных сценариев развития деловых отношений, либо благодарственное письмо как возможный сценарий пролонгации делового взаимодействия партнеров;

2) характеристика субъекта/объекта, представляющего деловой интерес, его рекламная презентация; письмо-предложение делового сотрудничества; письмо-ответ на предложение, благодарственное письмо;

3) информационное письмо (меморандум) с указанием реквизитов обратной связи (вопросы/предложения); письмо-реприманд (претензия), содержащее мотивацию негативного отношения к информации и требование отказа от реализации проекта; письмо-ответ на претензии; письмопредложение об урегулировании конфликтной ситуации; письмо-жалоба в надзорные или в судебные инстанции

Экспериенциальный подход к анализу коммерческой переписки позволяет учитывать не только логическую взаимосвязь структурных компонентов и традиционных реквизитов делового письма, но и характер их восприятия: интерпретации текстового, затекстного и подтекстного содержания как в иллокутивном, так и в перлокутивном аспектах. В частности, анализ синтаксических конструкций, а также пунктуационного членения текста, в том числе использование рубрицированной записи, позволяет объяснить, на какой информации предполагается сфокусировать внимание адресата, как предполагается трансформировать его представление о коннотативном значении предмета суждения, каково должно быть его моделируемое эмоциональное восприятие - эмпатия. Рубрицированная запись позволяет также предельно «загрузить» каждый из вычлененных однородных компонентов информацией, уточняющей содержание того или иного положения правоустанавливающего текста коммерческой деловой направленности. В отдельных случаях в структуру рубрицированной 
конструкции включаются самостоятельные высказывания, что разрушает привычные в практике ведения коммерческой документации представления о принципах графического оформления предложения (типа предложения в предложении).

В качестве примера рубрицированного текста можно привести следующий текст коммерческой санкционной ориентированности: «если Продавец не поставит товар в установленный в п. 1.2 настоящего контракта срок по причинам, за которые несет ответственность, он платит Покупателю штраф. Штраф начисляется, начиная с первого дня по истечении установленного п. 1.2 настоящего контракта срока в размере (\%) процента от стоимости непоставленного товара за каждый день просрочки. Штраф будет удерживаться с суммы, предназначенной для оплаты стоимости поставленного товара. В случае, если Покупатель по какой-либо причине не удержит штраф при оплате счета продавца, последний обязан оплатить сумму штрафа по первому требованию Покупателя. В случае, если просрочка поставки товара превысит (срок) месяца, Покупатель имеет право отказаться от контракта или его части. В целях исполнения контракта Покупатель может заключить договор с третьим лицом. Продавец в этом случае обязан возместить Покупателю расходы по заключению договора с третьим лицом и разницу между ценой товара, которая была предусмотрена настоящим контрактом, и ценой товара, который куплен у третьего лица».

Таким образом, проанализированная выше теория концентрации восприятия (М. Минский, 1978; Е. Кубрякова, 1994) позволяет рассматривать текст делового письма в перлокутивном аспекте речевого взаимодействия и объяснить, почему обмен коммерческой информацией носит тенденциозный, односторонний характер: на чем-то сделан смысловой акцент, а определенная часть информации сознательно представлена как факультативная или не получает вербального выражения, например, с помощью включения 
затекстного уровня содержания. Анализ коммерческой переписки с позиций когнитивной семантики в качестве реализации определенного стандартного сценария (инвариант «деловой ролевой игры») с помощью фреймовой сети деловых писем, а самого текста как «фрейма любого уровня обобщенности» (Ю. Караулов, 1987) позволяет детализировать их пропозициональную структуру: вычленить аргументацию, дать ее характеристики, установить логическую взаимосвязь суждений. Таким образом, создается концептуальная структура - модель текста делового письма различной функциональнотематической отнесенности. Семантика текста в полной мере определяется его темой - одной и важнейшей пропозицией (Т.А. Ван Дейк, 1998), а также коммуникативной целевой установкой адресанта, рассматриваемой в иллокутивном аспекте.

Различное форматирование когнитивного содержания (Zangacker, 1991; IX,2. P/ 5-12) может обусловливать конструирование информационного диалога в зависимости от различных фоновых предположений и ожиданий:

1) «B результате проведения (действие $\mathrm{X}$ ) принято решение $\mathrm{XX} . . . »-$ объективизация сообщения; эмоциональная стертость, внесубъективность позиции адресанта;

2) Благодаря проведению (действие $\mathrm{X}$ ) принято решение XX...» подчеркнутая положительная оценка, субъективация позиции адресанта;

3) В связи с проведением (действие X) принято решение ХХ... допускается отрицательно-оценочный информационный контекст.

В данном случае дифференцирование семантики производных предлогов позволяет точнее осмыслить и описать речевую ситуацию, а также форматировать концептуальное содержание высказывания как многофакторное.

Семантикой суждения (пропозиции) обусловлено использование различных средств репрезентации субъекта действия. Один и тот же концепт в 
преамбуле делового письма (например, коммерческого контракта или трудового договора) вербализован словосочетанием- гештальтом: должность (А) (генеральный директор/председатель правления/президент компании и т.п.) или функция (В) (специальный представитель/уполномоченное лицо) + название организации (C) + фамилия, имя, отчество (Д, Е,F), т.е. формулой AВСДЕF и затем трансформирован в конкретный концепт, например: клиент/заказчик/выгодополучатель. Значение используемого концепта активирует речевую функцию субъекта действия и соотносит его с определенной категорией, что также обозначает процесс категоризации. В результате подобной категоризации субъекта действия смещаются семантические акценты передаваемой в деловом письме информации: приоритетными становятся действие и его фоновые значения или обстоятельства.

Особенностыю семантики русского делового письма обусловлен и выбор синтаксической модели предложений. В частности, при описании конкретной ситуации адресант традиционно подчеркивает внесубъективность своей речевой позиции, что и определяет выбор синтаксических конструкций односоставных предложений: безличных либо определенно-личных. Стандартные формулировки типа: Рекомендуем.../ Предлагаем.../Просим.../Благодарим..., а также обозначение субъекта действия как некоего обобщенного лица (Мы...; Фирма...; Компания...) демонстрируют степень выделенности фокусирования внимания адресата. Анализ подобных синтаксических конструкций позволяет сделать выводы об особенностях пресуппозиции, о скрытых смыслах и специфике речевых тактик в процессе деловой коммуникации. В соответствии с теорией выделенности (prominence view) (Zandacker, 1991) можно объяснить характер отбора информации и ее презентацию в коммерческой корреспонденции, точнее определить характер речевого взаимодействия. 
Интерпретация текста делового письма, выявление косвенных и скрытых смыслов, подтекстного содержания передаваемой информации (прагматические пресуппозиции) осуществляется также и с позиций теории концентрации (фокусировки) внимания (Л. Талми, 1999). Деловая переписка, как фреймовая сеть, представляет собой «пакет информации». Знания о некоторой стереотипной коммерческой ситуации может быть представлено в виде двухуровневой структуры «узлов» и «отношений» (М. Минский, 1978): 1) вершинные узлы, которые содержат данные, всегда справедливые для данной ситуации: например, информация (меморандум) адресанта и реакция адресата (предложение о сотрудничестве или реприманд); 2) терминальные узлы (слоты), включающие данные, обусловленные конкретной деловой ситуацией и представляющие собой подфреймы или вложенные фреймы: например, благодарственное письмо или жалоба в надзорные, а также в судебные инстанции. Активизируя фреймовую сеть через данные второго уровня (слоты), возможно воссоздание всей структуры коммерческого взаимодействия в целом.

Таким образом, фоновые значения или обстоятельства действия (подфреймы) выполняют детерминирующую функцию, поясняя или конкретизируя деловую коммерческую ситуацию в целом, и являются ее пропозицией. Деловое письмо как текст коммерческой переписки по конкретной тематике в целом необходимо рассматривать не только с формальной точки зрения, описывая структурные элементы и композицию текстов, констатируя специфику их лексики, фразеологии и синтаксиса, но прежде всего с целью объяснения того, почему именно используемые языковые средства позволяют осуществлять деловую коммуникацию, и того, какие средства позволяют оптимизировать этот процесс. Именно поэтому каждому языковому явлению должно быть дано когнитивное обоснование и объяснение, что позволит глубже понять формы 
используемых языковых структур и описать существующие между ними зависимости.

Семантическая характеристика текстов коммерческих писем предполагает анализ их лексики, фразеологии и синтаксиса прежде всего с учетом специфики их восприятия: наличие соответствующих интенций, выделенности конкретных единиц, выбора определенной позиции в рамках информативного диалога (наличие или отсутствие перспективы коммуникации, т.е. стратегия делового взаимодействия).

\section{Зак.лютение.}

Исследование коммерческой переписки как особой формы речевого взаимодействия коммуникантов в ситуации делового общения с позиций прагматики предполагает экспериенциальный подход к структурным компонентам текстов, позволяющий определить их когнитивную семантику. При этом синтаксические средства исходя из их значения исследуются с позиций коммуникативного синтаксиса и его функционально-стилистических особенностей передачи информации.

Результаты новейших исследований в области психологии управления показывают, что коммуникативный режим общения, т.е. диалогичность формы речевого этикета, способствует оптимизации связей между и адресатом, что, в частности, благотворно влияет на различные области осуществления коммерческой деятельности. Следовательно, повышение речевой культуры является не только общегуманитарной, но и социально-экономической задачей.

Наметившееся в современном обществе стремление представителей административно-бюрократических структур выйти за рамки традиционных иерархических отношений в сфере деловой коммуникации объясняется тем, что существенно возросла цена внимания к интересам и правам конкретной 
личности. Ее уровень непосредственно влияет на так называемый рейтинг в политической и экономической конкурентной борьбе и в глобальном смысле на силу позиции адресанта в процессе переписки.

Однако новые тенденции, проявляющиеся в деловой коммерческой переписке, становятся в ситуации сохранения языковых конструкций «телеграфного стиля» причиной того, что большая часть современной деловой документации представляет собой пример стилистической эклектики и поэтому вызывает неоднозначное отношение к себе. В частности, проявляющееся в отдельных текстах коммерческой переписки стремление привлечь внимание адресата к своему бренду и своей товарной продукции зачастую воспринимается как неверное с точки зрения речевого этикета поведение, ассоциируемое с «агрессивной рекламой».

Подводя итог, следует подчеркнуть, что современная, демократическая форма делового этикета складывается в практике коммерческой переписки трудно и непоследовательно. Однако реалии нового времени заставляют преодолевать коммуникативные стереотипы авторитарных общественных отношений и переходить в коммуникативный режим диалога, что и определяет сущность новейших представлений о культуре письменной речи и об этикете коммерческой деятельности.

\section{Литература}

1- Венедиктова В.И. (1994). О деловой этике и этикете. Москва, Изд-во «Правовая культура».

2- Гофман И.А. (2003). Анализ фреймов: эссе об организации повседневного опьыта: пер. с англ./ Под ред. П.С. Батыгина и Л.А. Козловой. Москва.

3- Григорьев В.П. (1993). Из проилого лингвистической поэтики и интерлингвистики. Москва, «Изд-во Наука».

4- Дейк, Т.А. Ван (1989). Язык. Познание. Комиуникация: пер. с англ. /сост. В.В. Петрова. Под ред. В.В. Герасимова. Москва, Изд-во «Прогресс». 
5- Заботкина В.И. (2015). От интеграционного вызова в когнитивной науке $\kappa$ интгрированной методологии Методы когнитивного анализа семантики слова: компьютерно-корпусный подход. М., Изд-во «Языки славянской культуры». С. $15-38$.

6- Зандацкер П.Ш (1991). Цонцепт, Имаге анд Сьмбол: Тхе цогнитиве басис оф граммар. Н.Ь. Моутон де Груытер публишинг.

7- Караулов Ю.Н. (1987). Русский язык и языковая личность. Москва, Изд-во «Наука».

8- Кубрякова Е.С. (1994). Начальныле этапь становления когнитивизма. Лингвистика-психология-когнитивные науки /Вопросы языкознания. 1994. № 1. C. $34-37$.

9- Ланской Г.Н (2017). О взаимосвязи документоведения и архивоведения в информационном обществе // Вестник РГГУ. Серия "Документоведение и архивоведение. Информатика. Зацита информации и информачионная безопасность». 2017. № 1. С. $9-14$.

10- Лингвистический этимологический словарь (1990). Москва, Изд-во «Советская энциклопедия».

11- Минский М. (1978). Структура для предоставления знаний / Психология машинного зрения. Москва, Изд-во «Мир».

12- Соколов А.В. (2009). Эпистемология документа (методологический очерк) /Научно-техническая информачия. Серия 2. 2009. № 3. С. 1 - 12.

13- Талми Л. (1999). Отноиение грамиатики к познанио /Вестник Московского университета. Серия 9. Филология. № 1. С. $91-115$.

14- Теппер Р. (1997). Как овладеть искусством делового письма. 250 писем и записок в помоць менеджеру

\section{Bibliography}

1- Venediktova V.I. (1994). O delovoj jetike i jetikete. Moskva, Izd-vo «Pravovaja kul'tura».

2- Gofman I.A. (2003). Analiz frejmov: jesse ob organizacii povsednevnogo opyta: per. s angl./ Pod red. P.S. Batygina i L.A. Kozlovoj. Moskva.

3- Grigor'ev V.P. (1993). Iz proshlogo lingvisticheskoj pojetiki $i$ interlingvistiki.Moskva, «Izd-vo Nauka».

4- Dejk, T.A. Van (1989). Jazyk. Poznanie. Kommunikacija: per. s angl. /sost. V.V. Petrova. Pod red. V.V. Gerasimova. Moskva, Izd-vo «Progress». 
5- Zabotkina V.I. (2015). Ot integracionnogo vyzova $v$ kognitivnoj nauke $k$ intgrirovannoj metodologii Metody kognitivnogo analiza semantiki slova: komp'juterno-korpusnyj podhod. M., Izd-vo «Jazyki slavjanskoj kul'tury». S. 15 38.

6- Zandacker P.Shh (1991). Concept, Image and Symbol: The cognitive basis of grammar. N.Y. Mouton de Gruyter publishing.

7- Karaulov Ju.N. (1987). Russkij jazyk i jazykovaja lichnost'. Moskva, Izd-vo «Nauka».

8- Kubrjakova E.S. (1994). Nachal'nye jetapy stanovlenija kognitivizma. Lingvistikapsihologija-kognitivnye nauki /Voprosy jazykoznanija. 1994. № 1. S. 34 - 37.

9- Lanskoj G.N (2017). O vzaimosvjazi dokumentovedenija $i$ arhivovedenija $v$ informacionnom obshhestve // Vestnik RGGU. Serija «Dokumentovedenie $i$ arhivovedenie. Informatika. Zashhita informacii i informacionnaja bezopasnost'». 2017. № 1. S. 9 - 14.

10- Lingvisticheskij jetimologicheskij slovar' (1990). Moskva, Izd-vo «Sovetskaja jenciklopedija».

11- Minskij M. (1978). Struktura dlja predostavlenija znanij / Psihologija mashinnogo zrenija. Moskva, Izd-vo «Mir».

12- Sokolov A.V. (2009). Jepistemologija dokumenta (metodologicheskij ocherk) /Nauchno-tehnicheskaja informacija. Serija 2. 2009. № 3. S. $1-12$.

13- Talmi L. (1999). Otnoshenie grammatiki $k$ poznaniju /Vestnik Moskovskogo universiteta. Serija 9. Filologija. № 1. S. $91-115$.

14- Tepper R. (1997). Kak ovladet' iskusstvom delovogo pis'ma. 250 pisem i zapisokv pomosh 'menedzheru.

HOW TO CITE THIS ARTICLE

Guryeva Natalia Yurevna (2018). Commercial Correspondence: Pragmatics, Semantics, Syntax. Issledovatel'skiy zhurnal russkogo yazyka i literatury. 12(2):pp:111-132

DOI: 10.29252 /iarll.12.111

URL: http://journaliarll.ir/article-1-145-en.html

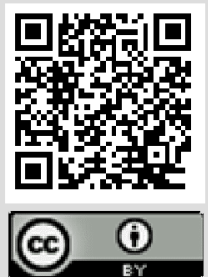




\title{
مكاتبات تجارى: كاربرد، معنا، ويزّخىهاى نحوى
}

\author{
ناتاليا يورىيونا كوريوا' \\ دانشيار، دانشكاه دولنى علوم انسانى روسيه،

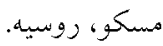

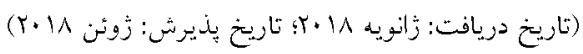

مقاله به بررسى و مطالعهُ ويزكى هاى مكاتبات تجارى و بازر كانى روسئه معاصر مى ئسردازد.

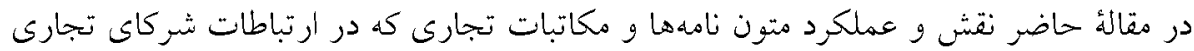

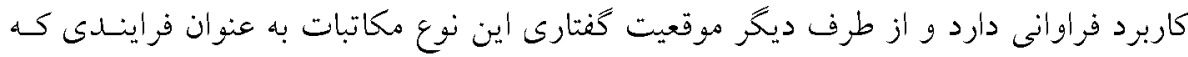

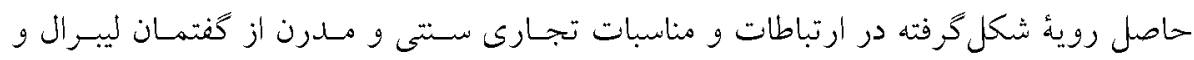

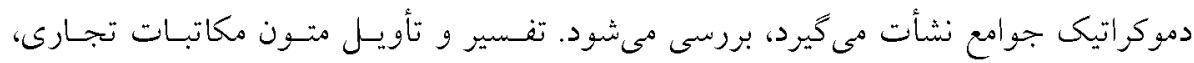

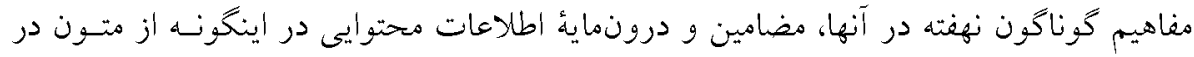

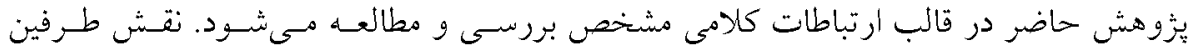

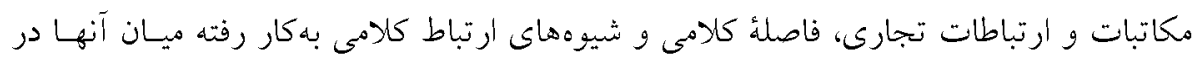

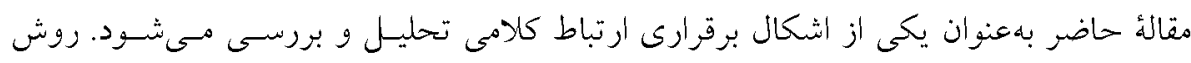

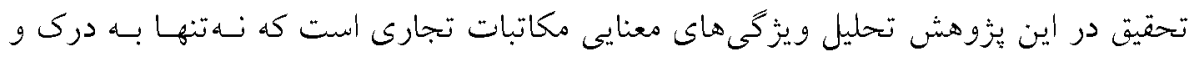

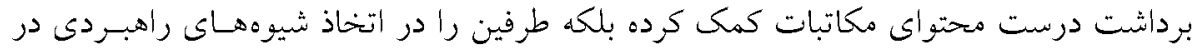

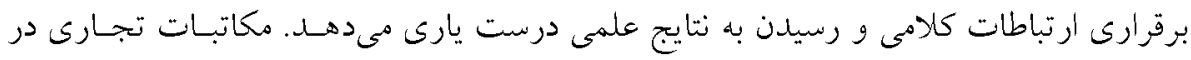

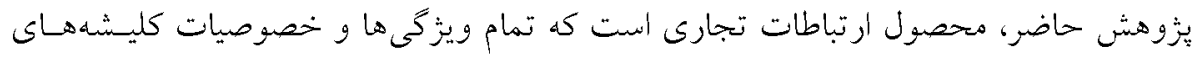

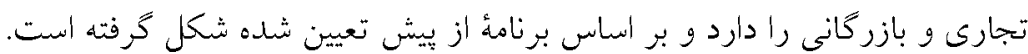

وازگًان كليدى: مكاتبات تجارى، نامة تجـارى، ارتباطـات كلامسى، معناشناسـى زبـانى، سـبك

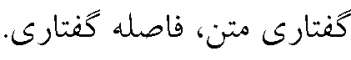

